\title{
Role of cyclophosphamide and high dose steroid in ocular cicatricial pemphigoid
}

\author{
Mark J Elder, Susan Lightman, John K G Dart
}

\begin{abstract}
Aims/background - Ocular cicatricial pemphigoid (OCP) can present with severe conjunctival inflammation that requires systemic immunosuppression to avoid serious ocular morbidity. This study aimed to assess the clinical response to cyclophosphamide and short term, high dose prednisolone in this group of patients.

Methods-A prospective, unmasked study assessed patients presenting with either 'severe' ocular inflammation $(n=4)$ or 'marked' or 'severe' ocular inflammation that had failed to respond to other systemic immunosuppression $(n=6)$. Nineteen inflamed eyes of 10 consecutive patients were enrolled.

Results-The ocular inflammation resolved in 15 eyes in a mean time of 2.4 months. Two eyes perforated despite treatment and one patient was unable to tolerate the medication. Progressive cicatrisation occurred in $21 \%$.

Conclusion-Cyclophosphamide and short term, high dose prednisolone are effective in severe inflammation caused by OCP but may not completely prevent cicatrisation. (Br F Ophthalmol 1995; 79: 264-266)
\end{abstract}

Moorfields Eye Hospital and Institute of Ophthalmology, London

M J Elder

S Lightman

J K G Dart

Correspondence to:

Mark J Elder, Moorfields Eye Hospital, City Road, London ECIV 2PD.

Accepted for publication 16 November 1994
Ocular cicatricial pemphigoid (OCP) is an inflammatory and cicatricial disease characterised by the systemic production and subsequent binding of antibodies to basement membrane. This is thought to activate complement and initiate a type II hypersensitivity reaction. ${ }^{1-3}$ A small number of patients develop severe conjunctival inflammation that is not responsive to topical or mild oral immunosuppressives. ${ }^{1-7}$ These patients are usually elderly and therefore the clinician must balance the potential harm of powerful immunosuppressive drugs with those of the ocular disease.

This study aimed to assess patients with severe conjunctival inflammation caused by OCP who were treated with cyclophosphamide and short term high dose oral prednisolone.

\section{Materials and methods}

Patients were selected from the Corneal and External Disease Clinics at Moorfields Eye Hospital over the 18 month period from September 1992. All patients with OCP were categorised from $0-4+$ by the amount of conjunctival inflammation. These were defined as: mild $(+)$, conjunctival hyperaemia only; moderate $(++)$, hyperaemia with conjunctival oedema; marked $(+++)$, significant conjunctival stromal and epithelial oedema; severe $(++++)$, very oedematous conjunctival stroma and epithelium in four quadrants. ${ }^{19}$ The inclusion criteria for this study were all patients with OCP who had 'severe' ocular inflammation $(n=4)$ or whom had 'marked' or 'severe' ocular inflammation that had failed to respond to systemic immunosuppression ( $n=6$, dapsone - three, sulphapyridine - three). All patients were consecutive and there were no exclusions. All patients had bilateral inflammation of a moderate degree or worse, except for one (patient no 1, Table 1). Other causes of conjunctival inflammation such as lid margin disease and trichiasis were resolved before entry into the study. Conjunctival biopsy was performed on all but one patient and was defined as diagnostic if

Table 1 Outcome of patients treated with cyclophosphamide and prednisolone

\begin{tabular}{|c|c|c|c|c|c|c|c|c|c|}
\hline Patient & Biopsy & Stage $e^{\star}$ & Inflammation $†$ & Limbitis & $\begin{array}{l}\text { Initial } \\
V A\end{array}$ & $\begin{array}{l}\text { Final } \\
V A\end{array}$ & Time for inflammation to resolve & $\begin{array}{l}\text { Duration of } \\
\text { cyclophosphamide }\end{array}$ & $\begin{array}{l}\text { Follow up } \\
\text { (months) }\end{array}$ \\
\hline 1 OS & + & $\begin{array}{l}\text { M4F3 } \\
\text { M4F3 }\end{array}$ & $\stackrel{+}{+++}$ & $\bar{t}$ & CF & CF & $\overline{4}$ Months & 6 Months & 6 \\
\hline $2 \mathrm{OS}$ & + & M4F3 & ++++ & + & $\begin{array}{l}0 / 9 \\
6 / 9\end{array}$ & $\begin{array}{l}6 / 12 \\
6 / 6\end{array}$ & $\begin{array}{l}4 \text { Months } \\
11 / 2 \text { months }\end{array}$ & & \\
\hline OD & & M2F2 & ++ & - & $6 / 9$ & $6 / 6$ & $1 \frac{1}{2}$ months & 14 Months & 14 \\
\hline $3 \mathrm{OS}$ & + & M4F3 & +++ & + & $6 / 24$ & $6 / 18$ & 4 Months, cicatrisation progressed & 12 Months & 12 \\
\hline OD & & M4F3 & ++++ & + & $6 / 18$ & $6 / 12$ & 4 Months, cicatrisation progressed & & \\
\hline 4 OS & - & M4F3 & +++ & + & $6 / 24$ & $6 / 9$ & 2 Months, switched to dapsone after 4 months & 4 Months & 25 \\
\hline $5 \stackrel{O D}{O S}$ & & M4F3 & ++++ & + & $6 / 9$ & $6 / 6$ & 2 Months, switched to dapsone after 4 months & & \\
\hline 5 OS & + & $\begin{array}{l}\text { M4F3 } \\
\text { M4F3 }\end{array}$ & $\begin{array}{l}+++ \\
++\end{array}$ & \pm & $6 / 9$ & $6 / 9$ & 1 Month & 18 Months & 18 \\
\hline 6 OS & Not done & M4F3 & ++++ & + & $\begin{array}{l}6 / 24 \\
\mathrm{CF}\end{array}$ & $\begin{array}{l}6 / 18 \\
\mathrm{CF}\end{array}$ & $\begin{array}{l}4 \text { Months } \\
1 \text { Month }\end{array}$ & 6 Months, & 6 \\
\hline OD & & M4F3 & ++++ & + & HM & HM & 1 Month & then deceased & \\
\hline 7 OS & + & $\begin{array}{l}\text { M4F3 } \\
\text { M4F3 }\end{array}$ & $\begin{array}{l}+++ \\
+++\end{array}$ & - & $\begin{array}{l}6 / 9 \\
6 / 12\end{array}$ & $6 / 12$ & Unable to tolerate the medication & $1 \frac{1}{2}$ months & 4 \\
\hline 8 OS & + & $\begin{array}{l}\text { M4F3 } \\
\text { M4F3 }\end{array}$ & $\begin{array}{l}+++ \\
++++\end{array}$ & + & $\begin{array}{l}6 / 12 \\
6 / 9\end{array}$ & $\begin{array}{l}6 / 18 \\
6 / 12\end{array}$ & Unable to tolerate the medication & 18 Months & 18 \\
\hline OD & & M4F3 & +++ & $\stackrel{+}{-}$ & $6 / 12$ & $6 / 24$ & $\begin{array}{l}2 \text { Months, cicatrisation progressed } \\
2 \text { Months, cicatrisation progressed }\end{array}$ & 18 Months & 18 \\
\hline 9 OS & + & $\begin{array}{l}\text { M4F3 } \\
\text { M4F3 }\end{array}$ & $\begin{array}{l}++++ \\
++++\end{array}$ & + & $\begin{array}{l}\text { PL } \\
\text { PL }\end{array}$ & NPL & $\begin{array}{l}\text { Perforated after } 2 / 12 \text { with microbial keratitis } \\
3 \text { Months, previous severe glaucoma }\end{array}$ & 3 Months & 19 \\
\hline $\begin{array}{l}10 \text { OS } \\
\text { OD }\end{array}$ & + & M4F3 & $\begin{array}{l}+ \\
++ \\
+\end{array}$ & $\bar{t}$ & $6 / 24$ & $6 / 36$ & 3 Months & 4 Months & 18 \\
\hline & & $14 \mathrm{~F} 3$ & +++ & & $6 / 18$ & C & Perforated after 1 month & & \\
\hline
\end{tabular}


there was basement membrane deposition of IgG, IgA, complement, or fibrinogen. Patients that were basement membrane antibody negative had characteristic subepithelial fibrosis and progressive conjunctival cicatrisation.

Each eye was staged according to the two systems of Mondino and Foster. ${ }^{2} 8-10$ Foster's stages are based on specific clinical signs; stage 2 - fornix shortening, stage 3 - symblepharon, stage 4 - ankyloblepharon. Mondino's stages are based on the lower fornix depth - for example, stage 3 is a loss of depth of $50-75 \%$. This depth was measured optically with a normal depth being defined as $11 \mathrm{~mm} .{ }^{11}$ Limbitis was defined as a raised, inflamed region involving the limbal tissues extending for one quadrant or more. The visual acuity data were that assessed at the initiation of cyclophosphamide and after the resolution of inflammation.

All patients were treated with oral cyclophosphamide at an initial dose of $1.5-2.0 \mathrm{mg} / \mathrm{kg} /$ day and oral prednisolone, $60 \mathrm{mg} /$ day $(\mathrm{n}=9)$ or $80 \mathrm{mg} /$ day $(\mathrm{n}=1)$. Other oral immunosuppressive agents were stopped. Success was defined as an objective improvement in the conjunctival inflammation to 'mild' $(+)$ or less. Patients were assessed at monthly intervals for 6 months and 2-3 monthly thereafter. Full blood counts and differential white blood counts were obtained at each visit. A proforma was used to record the data prospectively with the same observer (MJE) for all patients over the 18 months.

\section{Results}

Ten consecutive patients were enrolled. The mean age was 74.3 (SD 6.0) years and ranged from $62-82$ years. Nine patients were male and eight had a positive biopsy. At the onset of therapy, seven patients had severe ocular inflammation (unilateral or bilateral) and three patients had marked inflammation. Limbitis was present in 12 eyes of nine patients. All eyes were categorised as Mondino's stage 4 and Foster's stage 3 except for one which was stage 2 and 2 respectively (Table 1 ). Systemic manifestations of OCP were found in 7/10 patients; mouth or pharyngeal ulceration $(n=5)$, oesophageal ulceration $(n=4)$, bullous skin lesions $(n=1)$.

All patients remained on cyclophosphamide for more than 6 months except one (no 7). He developed marked feelings of being distant from the world, 'like being on [recreational] drugs'. These were so unpleasant that the cyclophosphamide was discontinued after 6 weeks. The symptoms abated within 3 days despite no change in the prednisolone dose. The ocular inflammation had reduced to 'moderate' bilaterally and ultimately became quiescent on dapsone. This patient is excluded from the following data.

The dose of cyclophosphamide was altered to achieve a lymphocyte count of $0 \cdot 5-1 \cdot 0 \times 10^{9} / 1$. This was achieved in all patients on a maintenance dose of $50-150$ $\mathrm{mg} /$ day, typically $100 \mathrm{mg} /$ day $(\mathrm{n}=7)$. No patient had reduced haemoglobin to less than $10 \mathrm{~g} / \mathrm{dl}$. The prednisolone was reduced rapidly to a small maintenance dose after a clinical response was observed. When the ocular and systemic features were judged to be clinically stable, the prednisolone was stopped and the cyclophosphamide was continued alone. The mean total duration of prednisolone was 5.9 months and ranged from 4-8 months.

Of the nine patients, $17 / 18$ eyes were inflamed. The ocular inflammation resolved in 15 eyes in a mean time of 2.4 months. During treatment, two eyes perforated, one of which was due to acute microbial keratitis (no 9). This patient had a poor ocular surface and a white blood count of $2.0 \times 10^{9} / 1$ at the time of the keratitis. The other perforation was the result of gradual corneal thinning that was not arrested with 1 month of medication (no 10). Progression of conjunctival cicatrisation occurred in four eyes of two patients (nos 3 and 8 ) and represents $21 \%$ of inflamed eyes (4/19).

During the study, one patient died, but this was unrelated to the medication. One man developed significant alopecia which reversed with a dose reduction of cyclophosphamide. No patient developed a systemic infection that required antibiotics.

Four patients have so far remained on cyclophosphamide for 1 year or more. This was because of ongoing systemic features $(n=2)$, relapse after stopping the medication $(n=1)$, and mild, persistent ocular inflammation $(n=1)$.

\section{Discussion}

The aims of treating OCP are to alleviate patients' ocular symptoms, reduce conjunctival inflammation, preserve corneal clarity, and to prevent further cicatrisation. Unfortunately, a small group of patients do not respond adequately to topical treatment or other comparatively safe systemic immunosuppression such as dapsone or sulphapyridine. ${ }^{14-7}$ This study examined these severe cases.

The first objective of management of these cases is to resolve the conjunctival inflammation. This current study illustrates that combined cyclophosphamide and prednisolone is effective at resolving severe conjunctival inflammation in the majority of patients. It has been particularly useful when other immunosuppressive agents such as dapsone and sulphapyridine have failed. Further, the visual acuity was preserved through these episodes of severe inflammation (Table 1 ).

The second objective of management is to prevent further cicatrisation. This happens most commonly during inflammatory episodes. ${ }^{101213}$ In this study, $21 \%$ had progressive cicatrisation despite adequate therapeutic reductions of the lymphocyte count and this is consistent with Mondino's experience. ${ }^{3}$

The rationale for this current combined treatment regimen is based on laboratory and clinical evidence. Histologically, these acutely inflamed eyes are infiltrated with neutrophils, macrophages, and $T$ lymphocytes and the majority have antibodies, complement, and 
fibrinogen bound to the conjunctival basement membrane. ${ }^{1415}$ Therefore, medical treatment should reduce acute inflammation and impair delayed hypersensitivity and the cell mediated immune system. This can be achieved with prednisolone and cyclophosphamide.

Clinically, high dose prednisolone on its own has been shown to be comparatively ineffective at reducing conjunctival inflammation. ${ }^{1} 1016$ Only $42 \%$ of patients with OCP had resolution of their inflammation. This required initial doses of $60-80 \mathrm{mg} /$ day and a mean maintenance dose of $40 \mathrm{mg} /$ day. ${ }^{16}$ Side effects included peptic ulceration (33\%), hypertension $(25 \%)$, diabetes (25\%), myopathy $(25 \%)$, osteoporosis (25\%), and psychosis $(25 \%)$. One third of these patients became 'blind' using the legal definition. ${ }^{16}$

Foster reported that cyclophosphamide ( $2 \mathrm{mg} / \mathrm{kg} /$ day) and a 3 month course of high dose prednisolone resolved the conjunctival inflammation in $100 \%$ of stage 3 patients and prevented recurrence and cicatrisation over 1 year. ${ }^{16}$ However, $100 \%$ developed some degree of anaemia, $83 \%$ developed alopecia, $8 \%$ developed haematuria, and $8 \%$ developed leucopenia. A later retrospective study suggested that cyclophosphamide was the most successful treatment in severe inflammation. ${ }^{6}$

Mondino et al assessed conjunctival cicatrisation over 24 months in a trial of cyclophosphamide, cyclophosphamide and prednisone, and placebo. ${ }^{2}$ Progression of conjunctival cicatrisation occurred in stage 1 in $25 \%, 17 \%$, and $40 \%$ of eyes respectively; in stage 2 in $10 \%, 21 \%$, and $62 \%$; and in stage 3 in $75 \%$, $25 \%$, and $73 \%$. This study suggests that combined cyclophosphamide and prednisone was the most effective treatment for prevention of cicatrisation but no regimen to date has completely prevented it.

Cyclophosphamide is a nitrogen mustard derived alkylating agent that affects DNA replication and RNA transcription. ${ }^{17}$ Side effects include alopecia, anovulation, azoospermia, haemorrhagic cystitis, bone marrow suppression, infection, and malignancy - especially bladder carcinoma. ${ }^{18-20}$ The risks of infection are highest in the first month and may be bacterial or viral.

These side effects are very important. The increased risk of infection may have contributed to the very poor outcome in the patient with microbial keratitis. The effects on fertility and the potential for malignancy are strong contraindications for young patients and the bone marrow suppression and risks of infection are significant problems for the elderly. In this series, the problems have been few but these patients have demanded much time of physicians, general practitioners, and laboratory services.

The authors have no financial interest in any of the products mentioned in this study.

The authors are grateful to Dr Jonathan Leonard, FRCP, $\mathrm{MD}$, for his help in managing these patients.

1 Foster CS. Cicatricial pemphigoid. Trans Am Ophthalmol Soc 1986; 84: 527-663.

2 Mondino BJ, Brown SI. Ocular cicatricial pemphigoid. Ophthalmology 1981; 88: 95-100.

3 Mondino BJ. Cicatricial pemphigoid and erythema multiforme. Ophthalmology 1990; 97: 939-52.

4 Person JR, Rogers RS III. Bullous and cicatricial pemphigoid: clinical, histopathologic, and immunopathologic correlations. Mayo Clin Proc 1977; 52: $54-66$

5 Rogers RS III, Seehafer JR, Perry HO. Treatment of cicatricial (benign mucous membrane) pemphigoid with dapsone. F Am Acad Dermatol 1982; 6: 215-23.

6 Tauber J, Sainz de la Maza M, Foster CS. Systemic chemotherapy for ocular cicatricial pemphigoid. Cornea 1991; 10: 185-95.

7 Elder MJ, Leonard J, Dart JK. Sulphapyridine - a new agent for the treatment of ocular cicatricial pemphigoid. (submitted)

8 Mondino BJ, Ross AN, Rabin BS, Brown SI. Autoimmune phenomena in ocular cicatricial pemphigoid. $\mathrm{Am} f$ Ophthalmol 1977; 83: 443-50.

9 Mondino BJ, Brown SI. Immunosuppressive therapy in ocular cicatricial pemphigoid. Am $\mathcal{f}$ Ophthalmol 1983; 96: 453-9.

10 Foster CS, Wilson LA, Ekins MB. Immunosuppressive therapy for progressive ocular cicatricial pemphigoid. Ophthalmology 1982; 89: 340-53.

11 Schwab IR, Linberg JV, Gioia VM, Benson WH, Chao GM. Foreshortening of the interior conjunctival fornix associated with chronic glaucoma medications. associated with chronic gla

12 Mondino BJ, Brown SI, Rabin BS. Auto immune phenomenon of the external eye. Trans Am Acad Ophthalmol 1978; 85: 801 .

13 Mondino BJ, Brown SI, Lempert S, Jenkins MS. The acute manifestations of ocular cicatricial pemphigoid: diagnosis and treatment. Ophthalmology 1979; 86: 543-52.

14 Sacks EH, Jakobiec FA, Wieczorek R, Donnenfeld E, Perry $H$, Knowles DM. Immunophenotypic analysis of the inflammatory infiltrate in ocular cicatricial pemphigoid. Further evidence for a T-cell mediated disease. Ophthalmology 1989; 96: 236-43.

15 Bernauer W, Wright P, Dart JKG, Leonard JN, Lightman $S$. The conjunctiva in acute and chronic mucous membrane pemphigoid: an immunohistochemical analysis. Ophthalmology 1993; 100: 339-46.

16 Hardy KM, Perry HO, Pingree GC. Benign mucous membrane pemphigoid. Arch Dermatol 1971; 104: 467-75.

17 Gilman AG, Goodman LS, Rall TW, Murad F. The pharmacological basis of therapeutics. New York: Macmillan, 1985.

18 Berkson BM, Lome LG, Shapiro I. Severe cystitis induced by cyclophosphamide, role of surgical management. by cyclophosphamide, role.

19 Dantzig PI. Immunosuppressive and cytotoxic drugs in dermatology. Arch Dermatol 1974; 110: 393-406.

20 Boitard C, Bach JF. Long term complications of conventional immunosuppressive treatment. Adv Nephrol 1989; 18: 335-54. 